\title{
Contact-Free Mortuary Trolley Design as a Device for the Mobility of Covid-19 Victims
}

\author{
Vania Katherine Mulia ${ }^{\mathrm{a}}$, Nanda Indriana ${ }^{\mathrm{b}}$, Qurriyatus Zahro ${ }^{\mathrm{c}}$, Farid Triawan ${ }^{\mathrm{d}, *}$ \\ ${ }^{a}$ Mechanical Engineering Department, Faculty of Engineering and Technology, Sampoerna University. \\ Email: vania.mulia@my.sampoernauniversity.ac.id \\ ${ }^{b}$ Mechanical Engineering Department, Faculty of Engineering and Technology, Sampoerna University. \\ Email: nanda.indriana@my.sampoernauniversity.ac.id \\ ${ }^{\mathrm{c}}$ Mechanical Engineering Department, Faculty of Engineering and Technology, Sampoerna University. \\ Email: qurriyatus.zahro@my.sampoernauniversity.ac.id \\ ${ }^{\mathrm{d}}$ Mechanical Engineering Department, Faculty of Engineering and Technology, Sampoerna University. \\ Email: farid.triawan@sampoernauniversity.ac.id
}

\begin{abstract}
The Covid-19 pandemic has caused many issues, especially in the medical field. One of the groups that are affected by the pandemic the worst is the health workers. The surge of demand for health services, especially for Covid-19 patients, overwhelms health workers, forcing them to work extra hard and eventually experience exhaustion. Due to this condition, the health workers may face difficulties in doing heavy-duty work. This paper proposes a design of a mortuary trolley as a device to ease the health workers in handling the dead bodies of Covid-19 victims. Considering the need for a corpse mobility aid that is contact-free, the design utilizes a combination of a scissor lift structure, a power screw mechanism to elevate and lower the table, and a conveyor system to load and unload the table. To ensure that the device can operate without experiencing unwanted failure, strength analyses are done on the most critical components, such as the scissor arm, pin joint, power screw, and scissor arm connector, to determine the safety factor at maximum load in static and fatigue loading condition. Analysis results show that all those components have a safety factor greater than 1 for both static and fatigue loading conditions, indicating the device will not yield and is predicted to have infinite life. The design and analyses of this device can be a reference for manufacturers of medical devices to design a mortuary trolley to ease the work of health workers.
\end{abstract}

Keywords: Engineering design; fatigue analysis; mortuary trolley; static analysis

\section{Introduction}

It has been more than a year since the first appearance of Covid-19 in the world and Indonesia, and this pandemic has not yet subsided and continues to make such big changes to our lives. A heavy burden is especially experienced by the health workers who must serve in the emergency room and make decisions about patient priorities. What is meant by health workers according to Undang-Undang No. 36 of 2014 is "everyone who devotes himself to the health sector and has the knowledge and/or skills through education in the health sector which for certain types requires the authority to make health efforts[1]. This group of health workers includes medical personnel such as doctors and nurses.

Currently, health workers must work harder than usual at the forefront of handling Covid-19 and many of them experience fatigue, burnout, to psychological stress. A study conducted by a research team from the Master of

\footnotetext{
${ }^{*}$ Corresponding author. Tel.: +62-21-5022-2234, Ext:7849

Jl. Raya Pasar Minggu, Kav 16
}

Jakarta Selatan, Indonesia, 12780
Work Medicine Study Program at the Faculty of Medicine, University of Indonesia (MKK FKUI) in 2020 showed 83 percent of health workers had burnout syndrome, which affects their performance in carrying out their duties and their quality of life [2]. In fact, many have died to deal with Covid-19 patients. Statistical data shows that as of April 26th, 2021, 900 health workers have died fighting Covid-19 [3]. The condition of health workers who are starting to become exhausted creates new problems, where various heavy jobs can become difficult.

One problem that can be highlighted is the process of handling the dead bodies of Covid-19 sufferers. In fact, there are still many processes in it that require health workers to move the bodies, for example from the corpse bed into the coffin or to the place where the corpse is bathed. Apart from being a heavy job to move them from one place to another, this has the potential to violate the health protocols proclaimed by the World Health Organization (WHO), in which physical contact must be minimized. In a situation like this, it is necessary to have a device that allows the transfer of the dead bodies 
without making any slightest physical contact. By modifying the shape of the existing mortuary trolley, a plate-shaped base supported by a conveyor feature connected to a slider mechanism can be added to allow for the lifting of the body with minimal force and a contact-free process. Hopefully, this tool can make it easier for exhausted health workers to carry out the process of caring for the corpse more safely and efficiently.

Based on the existing background, the objective of this paper is to find the most possible design of the mortuary trolley that allows the mobility of the dead body without any physical contact. This paper also explores how the mortuary trolley system works, as well as the advantages and constraints of the mortuary trolley design which will allow the mobility of the dead body without any physical contact. This design can be used as a reference for manufacturers of medical devices in producing a mortuary trolley for Covid-19 victim mobility purposes.

\section{Methodology}

To overcome this, an attempt is made to design a contact-free mortuary trolley. The design process is done according to the flow of mechanical design proposed by Shigley, which consists of the identification of needs, problem definition, synthesis, analysis and optimization, evaluation, and presentation [4]. During the synthesis stage, various sketches are made with different ideas of the mechanism, and design ranking is done to pick the best design based on the desired specifications [5]. The dimensions of the components are determined and optimized from the stress analyses in the analysis and optimization stage.

\subsection{Design concept}

Figure 1 shows the proposed design of the contactfree mortuary trolley, with the numbered parts corresponding to Table 1. The contact-free mortuary trolley is designed with several specifications. One of its specifications is that it can lift $250 \mathrm{~kg}$ in $150 \mathrm{~cm}$ of height at maximum. To satisfy the specification, this design is adopting a scissor lift working system to lift the dead bodies in up and down direction. The working system of a scissor lift is considered to be very advantageous in many applications due to its solid structure which can withstand a heavy load and provides smooth movement [6]. The strength of the scissor lift is derived from a pair of scissor arms which are strung together to form the letter 'X,' so the weight of the load placed on the platform is equally distributed on the two scissor arms. Furthermore, by stretching and folding the scissor arm arrangement, this crossing mechanism will increase and decrease the load. Usually, to increase the load, pressure is applied to the lower cross-section, so that the cross structure can extend vertically [7].

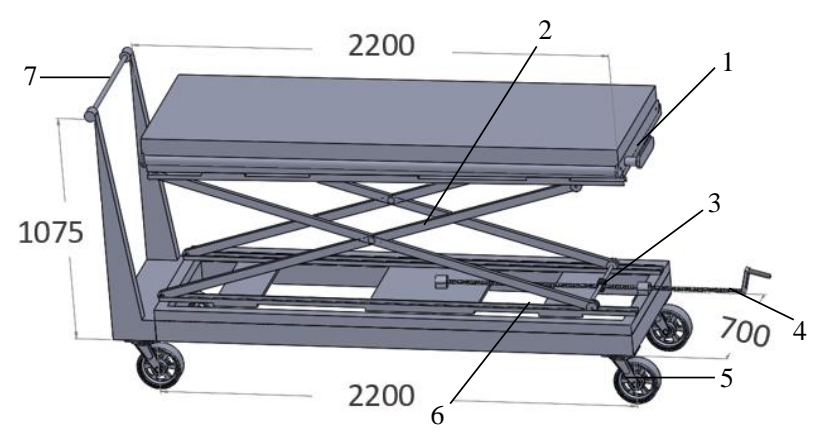

Figure 1. The final design of the mortuary trolley (dimension in $\mathrm{mm}$ )

Table 1. List name of the part

\begin{tabular}{cc}
\hline No & Name of the Part \\
\hline 1 & Conveyor System \\
2 & Scissor Lift \\
3 & Connector between Scissor lift and \\
4 & Power Screw \\
5 & Power Screw \\
6 & Wheel \\
7 & Wheel Rail \\
\hline
\end{tabular}

Initially, this mortuary trolley was designed with a hydraulic as a source of power so the arm will be able to move up and down. However, this idea will lead to failure in achieving one specification (Price estimation IDR 12-15 million) since hydraulic is considered to be having a high price on the market. Hence, the source of the power of the mortuary trolley is decided to be using a power screw. Furthermore, by turning the power screw with a ratchet handle on one side of the device, the heavy load received by the horizontally positioned power screw can be overcome through minimal effort applied to the power screw [8].

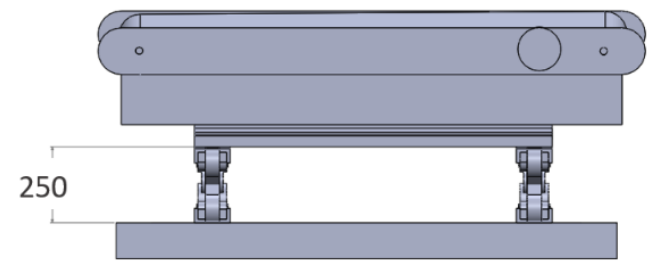

Figure 2. Illustration of the mortuary trolley in the minimum point (dimension in $\mathrm{mm}$ )

Figure 2 shows its lowest position. The height of the mortuary trolley is $250 \mathrm{~mm}$. This device is expected to be able to reach low places even in the process of moving corpses from one place to another so that this device can later be maximized its use without limitation in how low the area can be reached by this device. 


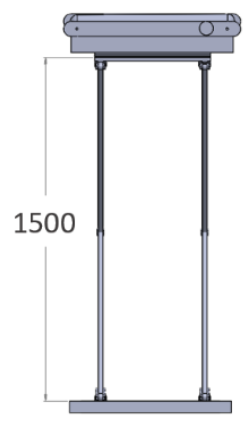

Figure 3. Illustration of the mortuary trolley in the maximum point (dimension in $\mathrm{mm}$ )

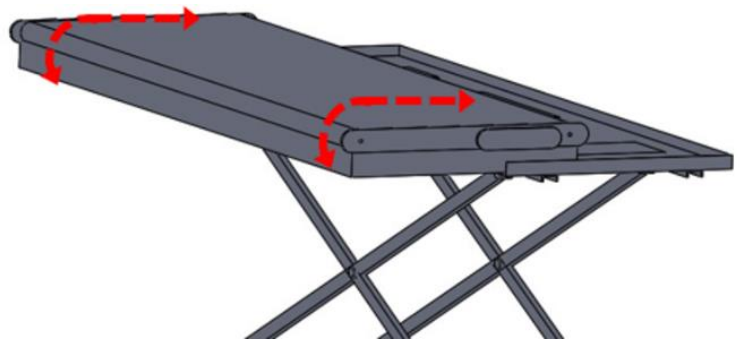

Figure 4. Illustration of the table slider at the furthest position with the conveyor direction

Figure 3 shows the condition of the scissor lift when the table is in its highest position. At the maximum point, the mortuary trolley can reach a height of about 1500 $\mathrm{mm}$. There is a possibility that some high enough areas that may generally require health workers have to lift corpses where we both know that the higher the load is lifted, the greater the energy required. Therefore, it is hoped that this tool can help a crucial part in removing corpses to a high enough area.

This design adopts a conveyor system that will be used to move dead bodies from one place to another with a contactless process. A conveyor mechanism is a mechanical system used to move material from one location to another location [9]. By adopting a conveyor system for the mobility of the movement of dead bodies, this tool can really minimize the physical touch that can cause the virus infection. This conveyor system is connected to a structure resembling a scissor lift which functions to control the height of the table where the bodies are placed. This conveyor will be in the form of a thin board with a cylindrical rod inside it which will move left or right to shift the dead body. The direction of the conveyor movement is indicated by the red arrows in Fig. 4.

The movement of the conveyor can be controlled by a lever that is connected to the end of one of the cylinder rods, and it can be rotated in both directions. In addition, this conveyor system is attached to a slider table that can slide sideways, with its furthest position as seen in Fig. 4. The goal of this slider table is to be positioned underneath the dead body while still on the bed or table, thus reducing the distance that the health worker needs to lift the dead body in order to move it from the bed or table to this mortuary trolley.

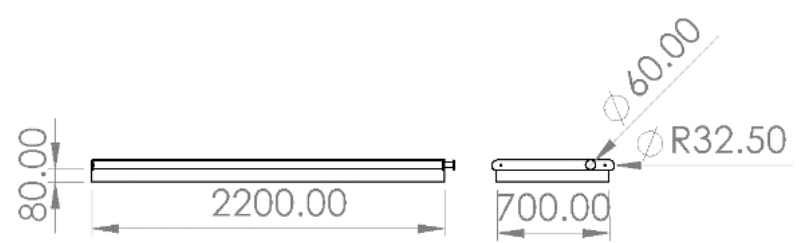

Figure 5. Conveyor part (dimension in $\mathrm{mm}$ )

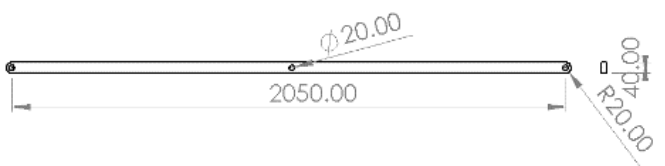

Figure 6. Scissor arm (dimension in $\mathrm{mm}$ )

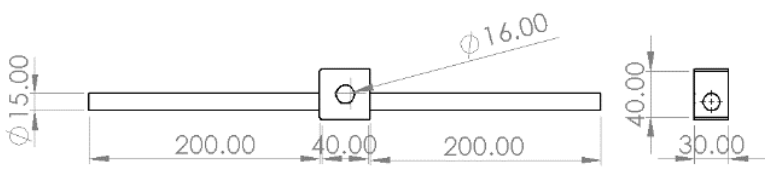

Figure 7. The connector between the scissor lift and power screw (dimension in $\mathrm{mm}$ )

Like a trolley, this design is equipped with four wheels and handrails, so it is easy to move. Furthermore, to facilitate the movement of dead bodies, it is necessary to develop further ideas through system modifications that can control the movement of platforms that have been facilitated by conveyors so that the movement of bodies can still be carried out with the appropriate moral values.

The design is divided into three main parts. The first is the conveyor part (Fig. 5), the second is the scissor lift part (Fig. 6), and the last is the power screw part (Fig. 7).

\subsection{Material selection}

The material for the mortuary trolley should be strong, not heavy, and safe for humans. This can encourage this tool to be operated by one person. Based on this condition, the suitable material is stainless steel. Stainless steel has corrosion-resistant properties and optimum hardness at room temperature, so stainless steel is essential for medical, chemical, cryogenic, and biotechnological applications [10]. Furthermore, stainless steel also has strong strength, good formability, and good weldability [11]. This proposed design, therefore, uses stainless steel material for the frame, power screw, and scissor lift. The dimensions have been optimized to be compact enough for a small weight.

The material that is used is stainless steel 304. Stainless steel 304 has several material properties that are shown in Table 2 [12].

Table 2. Mechanical properties of stainless steel 304

\begin{tabular}{ccc}
\hline Mechanical Properties & Metric & English \\
\hline Density & $8.00 \mathrm{~g} / \mathrm{cc}$ & $0.289 \mathrm{lb} / \mathrm{ln}^{2}$ \\
Hardness, Rockwell B & 70 & 70 \\
Tensile Strength, & $505 \mathrm{MPa}$ & $73200 \mathrm{psi}$ \\
Ultimate & $215 \mathrm{MPa}$ & $31200 \mathrm{psi}$ \\
Tensile Strength, Yield & $193 \mathrm{GPa}$ & $28000 \mathrm{ksi}$ \\
Modulus of Elasticity & & \\
\hline
\end{tabular}




\subsection{Strength analysis procedure}

Analyses must be done to ensure that the device is functional and that it does not experience unwanted failure, either due to static or fatigue loading. To do this, the load is assumed on the device at the most critical condition, which is when the table is at its highest position. In this position, the scissor arm connected to a pin-sliding joint will be the closest to the midpoint of the table where the load is concentrated. This position will force the scissor arm to withstand the maximum possible load.

To describe the safety of the device, strength analyses are performed for the most critical components, which are the scissor arm, the power screw/thread used to control the table's height, the connecting pins, and the connector between the scissor arms and the thread. A free-body diagram (FBD) is made for each component, and by applying the force and moment equilibrium equations, all the forces exerted on each body can be found. From the FBD, shear force diagrams (SFD) and bending moment diagrams (BMD) can be drawn to find the location at which the body experiences the greatest bending moment and thus the greatest stress [13]. In addition, the torque in the power screw required to raise the table is also calculated, assuming that the thread is an Acme thread. Eventually, the stresses can be calculated and the safety factor under static loading can be found using the distortion-energy failure criterion.

For fatigue analysis, the components are assumed to experience fluctuating load between maximum loaded and unloaded. The maximum stress value is taken from the static force analysis, while the minimum stress value is taken to be zero (unloaded). The fatigue analysis is done by calculating the endurance limit, Marin factors, midrange and alternating stresses, and finally the fatigue safety factor. Soderberg fatigue failure criterion is used as it is the most conservative criterion.

The formula used in the analysis are [4], [14]:

$$
\begin{gathered}
\sigma_{b}=\frac{M c}{I} \\
\sigma_{a}=\frac{P}{A} \\
T_{R}=\frac{F d_{m}}{2}\left(\frac{l+\pi f d_{m} \sec \alpha}{\pi d_{m}-f l \sec \alpha}\right) \\
\tau=\frac{16 T_{R}}{\pi d_{r}^{3}}(\text { for power screw }) \\
\sigma^{\prime}=\frac{1}{\sqrt{2}}\left[\left(\sigma_{x}-\sigma_{y}\right)^{2}+\left(\sigma_{y}-\sigma_{z}\right)^{2}\right. \\
\left.+\left(\sigma_{z}-\sigma_{x}\right)^{2}+6\left(\tau_{x y}^{2}+\tau_{y z}^{2}+\tau_{z x}^{2}\right)\right]^{1 / 2} \\
n_{s}=\frac{S_{y}}{\sigma^{\prime}} \\
n_{f}=\left(\frac{\sigma_{a}}{S_{e}}+\frac{\sigma_{m}}{S_{u t}}\right)^{-1}
\end{gathered}
$$

\begin{tabular}{|c|c|}
\hline$\sigma_{b}$ & : normal stress due to bending (MPa) \\
\hline$M$ & : bending moment (N.m) \\
\hline$c$ & $\begin{array}{l}\text { : maximum distance from the bending } \\
\text { neutral axis }(\mathrm{m})\end{array}$ \\
\hline$I$ & $\begin{array}{l}\text { : area moment of inertia about the neutral } \\
\text { axis }\left(\mathrm{m}^{4}\right)\end{array}$ \\
\hline$\sigma_{a}$ & : normal stress due to axial load (MPa) \\
\hline$P$ & : axial load $(\mathrm{N})$ \\
\hline$A$ & : cross-section area $\left(\mathrm{m}^{2}\right)$ \\
\hline$T_{R}$ & : torque required to raise the load (N.m) \\
\hline$F$ & : loading force $(\mathrm{N})$ \\
\hline$d_{m}$ & : power screw mean thread diameter $(\mathrm{m})$ \\
\hline$l$ & : power screw thread lead $(\mathrm{m})$ \\
\hline$f$ & : friction coefficient between the power \\
\hline & screw thread and nut element \\
\hline$\alpha$ & : power screw thread angle (degrees) \\
\hline$\tau$ & : shearing stress due to torsion $(\mathrm{MPa})$ \\
\hline$d_{r}$ & : power screw thread minor diameter $(\mathrm{m})$ \\
\hline$\sigma^{\prime}$ & : Von Mises stress (MPa) \\
\hline$\sigma_{x}, \sigma_{y}, \sigma_{z}$ & $\begin{array}{l}\text { : normal stress in the } \mathrm{x}, \mathrm{y}, \text { and } \mathrm{z} \text { direction } \\
(\mathrm{MPa})\end{array}$ \\
\hline$\tau_{x y}, \tau_{y z}, \tau_{z x}$ & $\begin{array}{l}\text { shear stress in the } \mathrm{x}-\mathrm{y}, \mathrm{y}-\mathrm{z}, \text { and } \mathrm{z}-\mathrm{x} \\
\text { direction }(\mathrm{MPa})\end{array}$ \\
\hline$n_{s}$ & : safety factor under static loading \\
\hline$S_{y}$ & : yield strength $(\mathrm{MPa})$ \\
\hline$n_{f}$ & : safety factor under fatigue loading \\
\hline$\sigma_{a}$ & $\begin{array}{l}\text { : amplitude of the alternating component of } \\
\text { stress }(\mathrm{MPa})\end{array}$ \\
\hline$\sigma_{m}$ & $\begin{array}{l}\text { midrange steady component of stress } \\
(\mathrm{MPa})\end{array}$ \\
\hline$S_{e}$ & : endurance limit $(\mathrm{MPa})$ \\
\hline$S_{u}$ & : ultimate tensile strength $(\mathrm{MPa})$ \\
\hline
\end{tabular}

where,

\section{Results and Discussion}

\subsection{Static analysis}

For the scissor lift structure itself, static analysis is performed only for one side of the scissor lift. The maximum load $(2500 \mathrm{~N})$ is assumed to be evenly distributed to both sides of the scissor lift. Although there is a conveyor mechanism and a table slider which can shift the load sideways, the table slider is expected to still be supported by the bed or table on which the dead body is initially placed, thus not accounted as the critical condition of this trolley. The weight of the components is neglected in this calculation. The FBD of the scissor lift structure can be seen in Fig. 8. The joints at point B and $\mathrm{G}$ are pin-sliding joints, while at point $\mathrm{D}, \mathrm{E}$, and $\mathrm{H}$ they are pin joints. 


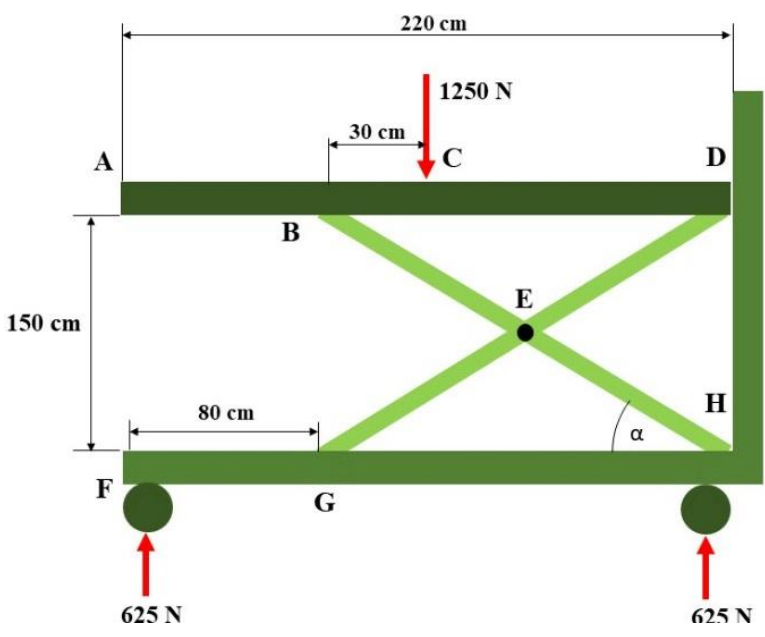

Figure 8 . FBD of the scissor lift structure
From the FBD in Fig. 8, the forces at each joint can be found by applying the equation of equilibrium of forces and moments. Then, the FBD of each component can be drawn to find the forces exerted on each component. Figures 9, 10, 11, and 12 show the FBD and the found forces for the scissor lift table, scissor arms, pin joint, and scissor arm connector, respectively. The load is initially transferred from the scissor lift table (Fig. 9) to the scissor arms as reaction forces at points B and D. In the scissor arms (Fig. 10), there are also reaction forces at the pin joint connecting each other at point $E$. The pin at point E experiences transverse load from both scissor arms (Fig. 11), represented by two distributed loads along the scissor arms' thickness. Finally, the connector between the two sides of the scissor lift structure experiences a three-point bending (Fig. 12) due to the force at point $\mathrm{G}$ in the $\mathrm{x}$-direction.

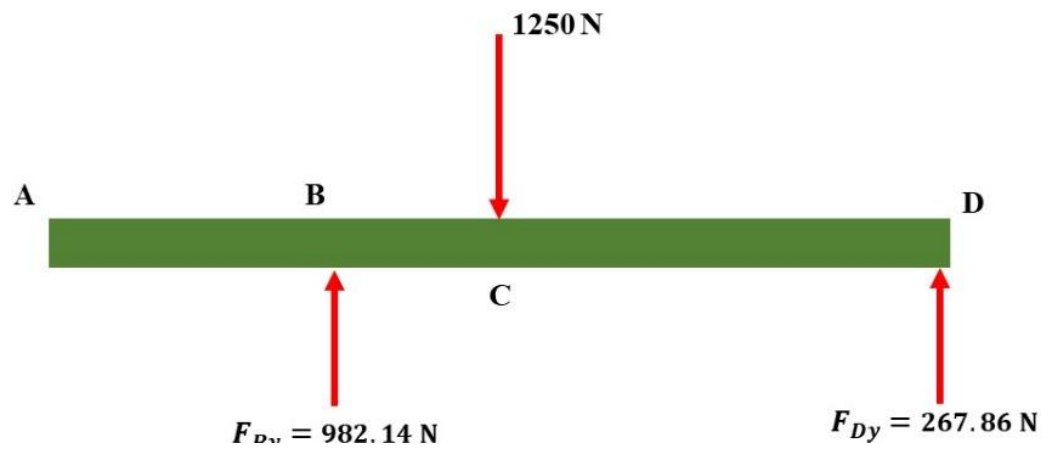

Figure 9. FBD of the scissor lift table

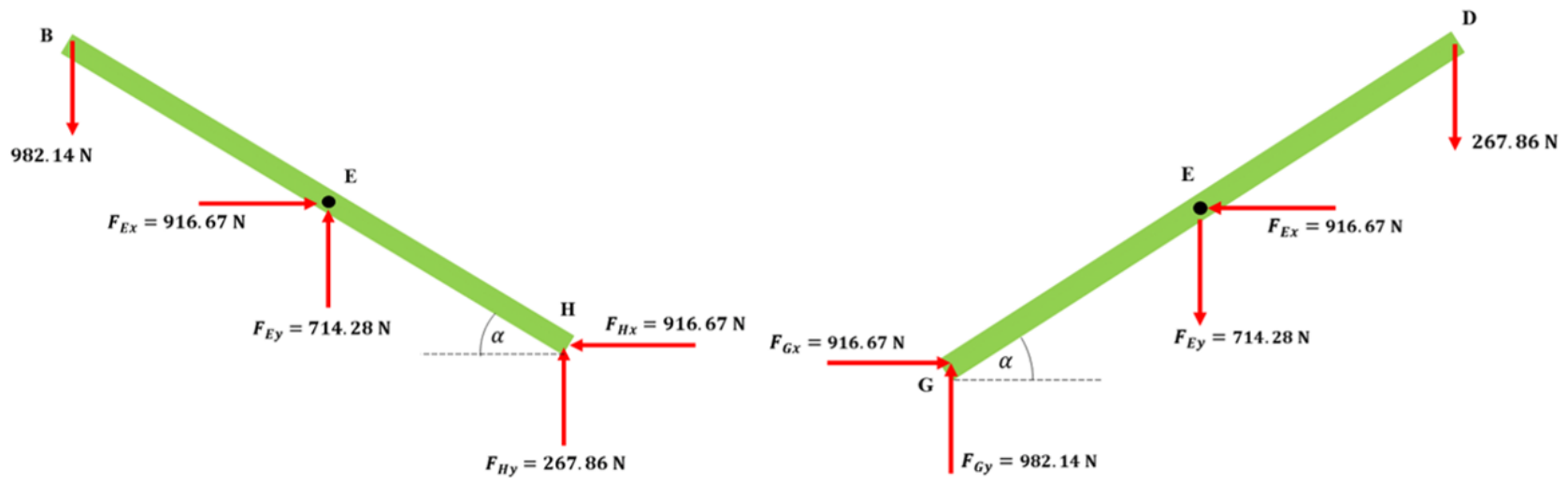

Figure 10. FBD of scissor arms

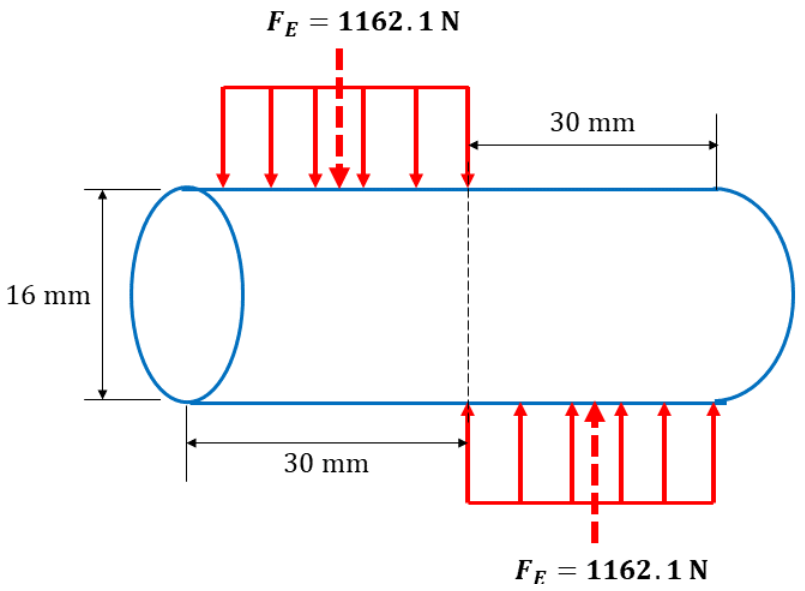

Figure 11. FBD of pin 


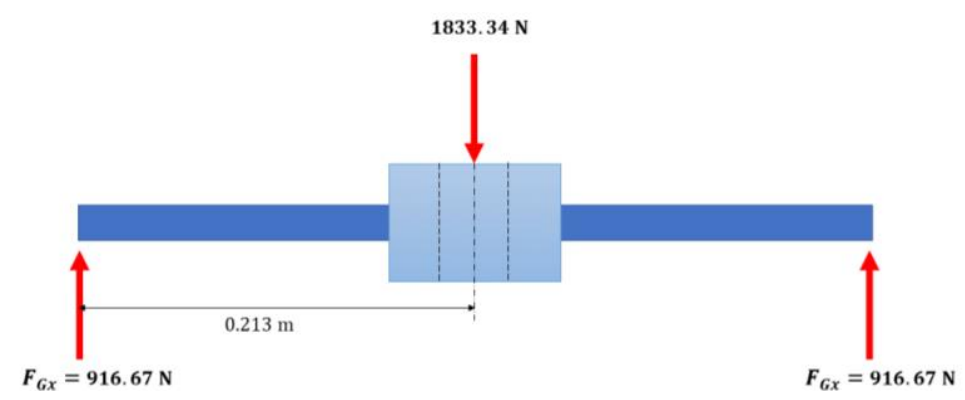

Figure 12. FBD of scissor arm connector

Based on calculations, the most critical component is the scissor arm, specifically the one passing through points B-E-H (Fig. 10, left). For analysis purposes, the scissor arm is rotated so that it is positioned. The forces are projected to the transverse direction to determine the transverse forces and bending moments. This projection can be seen in Fig. 13. The axial components of the forces are ignored in further analyses because the normal stress generated is relatively much smaller than the normal stress due to bending. The SFD and BMD of this scissor arm can be seen in Fig. 14.

a.

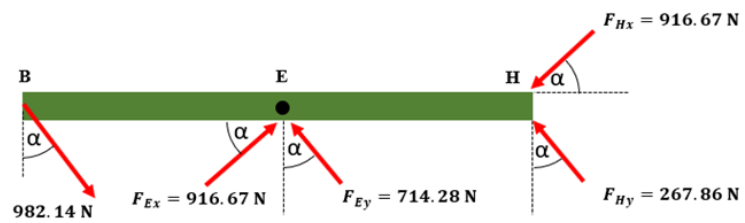

b.

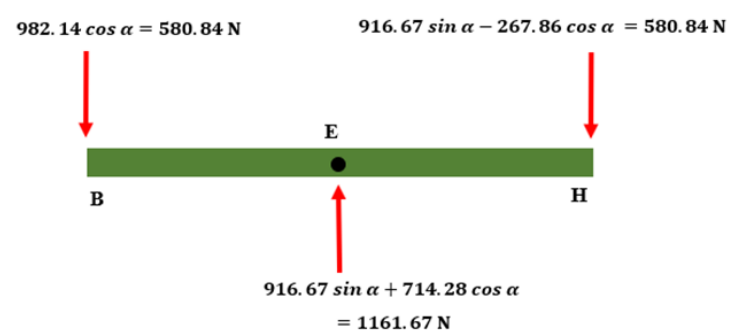

Figure 13. (a) Rotated scissor arm B-E-H and its forces, (b) Projected transverse load on scissor arm B-E-H

\section{SFD}
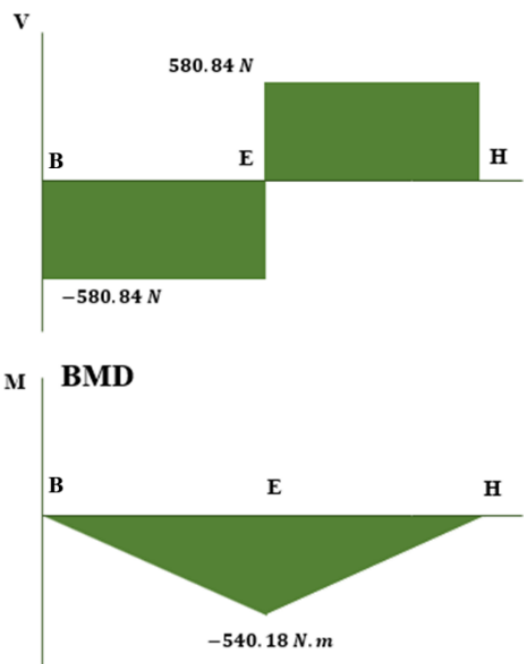

Figure 14. SFD and BMD of scissor arm
Based on the BMD in Fig. 14, the maximum bending moment occurs at point $\mathrm{E}$. The normal stress can be calculated using Eq. 1, where $b=30 \mathrm{~mm}=0.03 \mathrm{~m}, c=$ $25 \mathrm{~mm}=0.025 \mathrm{~m}$, and $I$ can be expressed as

$$
I=\frac{1}{12} b(2 c)^{3}
$$

Thus, Eq. 1 can be rewritten as

$$
\sigma_{b}=\frac{3 M}{2 b c^{2}}=\frac{3(540.18)}{2(0.03)(0.025)^{2}}=43.21 \mathrm{MPa}
$$

At point E, stress concentration exists because of the existence of a pinhole. According to the geometry of the scissor arm, the stress concentration factor $K_{t}$ is found to be 1.9. The Von Mises stress can be found using Eq. 5 where only one component exists which is

$$
\sigma_{x}=1.9(43.21)=82.1 \mathrm{MPa}
$$

Thus, the Von Mises stress is $\sigma^{\prime}=82.1 \mathrm{MPa}$. For the material chosen (stainless steel 304), the yield strength $S_{y}$ is $215 \mathrm{MPa}$. Thus, the safety factor under static loading can be calculated using Eq. 6 .

$$
n_{s}=\frac{215}{82.1}=2.62
$$

and since the value is greater than 1 , thus yielding will not occur. The safety factor for other components are calculated using similar steps, and the result can be seen in Table 3. It can be seen that all safety factors are greater than 1 , thus the device is considered safe under static loading.

\subsection{Power screw analysis}

Parallel to the static stress analysis, additional analysis is done to the power screw to determine the torque required to lift the scissor lift table. This torque will be exerted by a human hand; thus, it has to be made sure that the value is reasonable to allow easy usage of the device.

Table 3. The safety factor of all critical components under static loading

\begin{tabular}{cc}
\hline Component & $n_{s}$ \\
\hline Scissor arm & 2.62 \\
Pin & 4.97 \\
Power screw & 4.2 \\
Connector & 3.61 \\
\hline
\end{tabular}


The torque required to raise the load can be calculated using Eq. 3 [4]. The load $\mathrm{F}$ is $1833.33 \mathrm{~N}$ according to the static force calculation. In addition, the friction coefficient $f$ is assumed to be 0.25 , based on experimental data for steel on steel in dry condition. Thus, the torque needed is

$$
\begin{aligned}
T_{R} & =\frac{1833.33(0.0135)}{2}\left(\frac{5 \times 10^{-3}+\pi(0.25)(0.0135) \sec 30^{\circ}}{\pi(0.0135)-0.25\left(5 \times 10^{-3}\right) \sec 30^{\circ}}\right) \\
& =5.21 \mathrm{~N} . \mathrm{m}
\end{aligned}
$$

In addition, a self-locking condition is desired. This is necessary to ensure that the table stays in its position when loaded. The condition of self-locking is [4]:

$$
\begin{aligned}
\frac{\pi f d_{m}}{\cos \alpha} & >l \\
\frac{\pi(0.25)(0.0135)}{\cos 30^{\circ}} & >5 \times 10^{-3} \\
0.0122 & >5 \times 10^{-3}
\end{aligned}
$$

Since the inequality is satisfied, thus, the power screw will self-lock.

For the stress analysis, the thread experiences three components of stress. They are normal stress due to compression from the load, shear stress due to torsion, and normal stress due to bending at thread root [4]. These stresses can be calculated using Eq. 1 for bending stress, (2) for axial stress, (4) for shear stress due to torsion. The formulae for normal stresses are modified according to the thread geometry. Thus, the stress components are calculated by

$$
\begin{aligned}
\sigma_{x} & =\sigma_{b}=\frac{6(0.38 F)}{\pi d_{r} n_{t} p} \\
& =\frac{6(0.38)(1833.33)}{\pi(0.011)(1)\left(5 \times 10^{-3}\right)} \\
& =24.19 \mathrm{MPa} \\
\sigma_{y} & =\sigma_{a}=-\frac{4 F}{\pi d_{r}^{2}} \\
& =-\frac{4(1833.33)}{\pi(0.011)^{2}} \\
& =-19.3 \mathrm{MPa} \\
\tau_{y z} & =\frac{16 T_{R}}{\pi d_{r}^{3}}=\frac{16(5.21)}{\pi(0.011)^{3}} \\
& =19.94 \mathrm{MPa}
\end{aligned}
$$

Calculating the Von Mises stress using Eq. 5, the value is obtained as $51.16 \mathrm{MPa}$. The safety factor under static loading can be found using Eq. 6, and the value obtained is 4.2 (as can be seen in Table 3) which indicates no yielding.

\subsection{Fatigue analysis}

Fatigue analyses are done by considering the loaded and unloaded conditions. To determine the life period of the device, the endurance limit is first determined by

$$
S_{e}^{\prime}=\frac{1}{2} S_{u t}=\frac{1}{2}(505)=252.5 \mathrm{MPa}
$$

Table 4. Endurance limit of all critical components under fatigue loading

\begin{tabular}{cc}
\hline Component & $S_{e}(\mathrm{MPa})$ \\
\hline Scissor arm & 188.92 \\
Pin & 225.17 \\
Power screw & 219.675 \\
Connector & 186.72 \\
\hline
\end{tabular}

The endurance limit is modified by the Marin factors. There are six Marin factors in total, however, only three are considered in this analysis: surface factor $\left(k_{a}\right)$, size factor $\left(k_{b}\right)$, loading factor $\left(k_{c}\right)$. The other three factors, which are temperature factor $\left(k_{d}\right)$, reliability factor $\left(k_{e}\right)$, and miscellaneous factor $\left(k_{f}\right)$ are assumed unity. Thus, the real endurance limit can be determined by

$$
S_{e}=k_{a} k_{b} k_{c} k_{d} k_{e} k_{f} S_{e}^{\prime}
$$

The endurance limit of each component can be seen in Table 4.

Based on the calculation, the most critical part is the scissor arm which is the same component as in static analysis. At the most critical point, which is at point E, stress concentration exists due to the existence of a pinhole. The fatigue stress concentration factor $\left(K_{f}\right)$ can be calculated by

$$
K_{f}=1+\frac{K_{t}-1}{1+\sqrt{\frac{a}{r}}}
$$

where $\sqrt{a}$ is defined as the Neuber constant, and it can be expressed as a curve fit equation of the notch sensitivity chart for steels subjected to reversed bending or reversed axial loads [4].

$$
\begin{aligned}
\sqrt{a} & =0.246-3.08\left(10^{-3}\right) S_{u t}+1.51\left(10^{-5}\right) S_{u t}^{2}-2.67\left(10^{-8}\right) S_{u t}^{3} \\
& =0.246-3.08\left(10^{-3}\right)(73.2441)+1.51\left(10^{-5}\right)(73.2441)^{2} \\
& -2.67\left(10^{-8}\right)(73.2441)^{3} \\
& =0.091
\end{aligned}
$$

In the above formula, the ultimate tensile strength $S_{u t}$ is in kpsi. Referring back to Eq. 8, the fatigue stress concentration factor is

$$
K_{f}=1+\frac{1.9-1}{1+\frac{0.091}{\sqrt{8}}}=1.872
$$

The maximum stress is $43.21 \mathrm{MPa}$, which is the normal stress due to bending found in the static analysis before amplified by the static stress concentration factor. The minimum stress is taken as zero which indicates the unloaded condition. The midrange and alternating stresses can be found by

$$
\begin{aligned}
\sigma_{m} & =K_{f} \frac{\sigma_{\max }+\sigma_{\min }}{2} \\
& =1.872\left(\frac{43.21+0}{2}\right) \\
& =40.44 \mathrm{MPa}
\end{aligned}
$$




$$
\begin{aligned}
\sigma_{a} & =K_{f}\left|\frac{\sigma_{\max }-\sigma_{\min }}{2}\right| \\
& =1.872\left|\frac{43.21-0}{2}\right| \\
& =40.44 \mathrm{MPa}
\end{aligned}
$$

Finally, the safety factor under fatigue loading can be calculated using the Soderberg fatigue failure criterion, expressed as Eq. 7, where a safety factor greater than 1 means infinite life.

$$
n_{f}=\left(\frac{40.44}{188.92}+\frac{40.44}{215}\right)^{-1}=2.49
$$

Since the safety factor due to fatigue is greater than 1 , infinite life is predicted for the scissor arm. A similar process is done on other critical components to get the fatigue safety factor. Table 5 shows the safety factor due to fatigue loading of all critical components. It can be seen that all safety factors are greater than 1 , thus it is predicted that the device has infinite life.

All of the above analyses are done with the assumption of ideal condition with no other defects. Future studies may include measuring the residual stress from the fabrication process, especially the machining process [15]. In addition, stress analysis using Finite Element Analysis (FEA) may also be done to show the stress condition of the whole system more accurately [16].

\section{Conclusion}

Health workers, as a group of people who are very vulnerable to the exposure of this Covid-19 virus because of their frequent interactions with the sufferers, need more attention and support so that they can do their duties well. With this condition, a contact-free mortuary trolley is proposed complete along with its design and analysis to help health workers on moving the dead bodies of Covid 19 sufferers without any physical contact. This mortuary trolley is designed with 3 main parts, the first one is the lower section of the frame where the wheels are installed, 4 scissor arms that will function as a mechanism to lift up and down the trolley table, and the last one is the trolley table where the table is equipped with a thin conveyor mechanism. From the analysis of each part at its maximum position, it is found that the most critical part is the scissor arm of the trolley because as the trolley is at its maximum position, the scissor arm will experience the most load and forces from the whole device. However, by calculating the safety factor of the device in either static loading or fatigue loading conditions with a value greater than 1 , it is estimated that this tool will be safe in operation to achieve the expected objectives. Therefore, this paper is proposed with great hope so that this trolley can actually be produced and contribute to the medical field.

\section{References}

[1] "hukumonline.com."

[2] Fakultas Kedokteran Universitas Indonesia, "83\% Tenaga Kesehatan Indonesia Mengalami Burnout Syndrome Derajat Sedang dan Berat Selama Masa Pandemi COVID-19 - FKUI," 2020. https://fk.ui.ac.id/berita/83-tenaga-kesehatan-indonesiamengalami-burnout-syndrome-derajat-sedang-dan-berat-selamamasa-pandemi-covid-19.html (accessed Mar. 04, 2021).

[3] Lapor Covid-19, "TERIMA KASIH PAHLAWAN KESEHATAN INDONESIA,” 2021. https://nakes.laporcovid19.org/ (accessed Mar. 04, 2021).

[4] R. G. Budynas and J. K. Nisbett, Shigley's Mechanical Engineering Design, 10th ed. McGraw-Hill Education, 2015.

[5] M. Oktaviandri and D. K. A. V Paramasivam, "Design and Fabrication of Customized Ais Kacang Vending Machine," Indones. J. Comput. Eng. Des., vol. 2, no. 1, p. 24, 2020, doi: 10.35806/ijoced.v2i1.100.

[6] G. G. Momin, R. Hatti, K. Dalvi, F. Bargi, and R. Devare, "Design, Manufacturing \& Analysis of Hydraulic Scissor Lift," Int. J. Eng. Res. Gen. Sci., vol. 3, no. 2, pp. 733-740, 2015.

[7] M. K. Kumar, J. Chandrasheker, M. Manda, and D. V. Kumar, ““ Design \& Analysis of Hydraulic Scissor Lift ,"” pp. 1647-1653, 2016.

[8] M. O. Stanley, "A Project on Scissor Lift Design for Use in The Automotive Industry," no. August, 2012.

[9] D. Dave, "Study and Performance of Belt Conveyor System with Different Type Parameter," vol. 2, no. 06, pp. 29-31, 2015.

[10]H. M. Hdz-Garcia et al., "304 Stainless Steel Brazing Inxoporating Tungsten Nanoparticles," J. Mater. Process. Technol., vol. 215, pp. $1-5,2015$.

[11]M. Mukherjee and T. Pal, "Microstructure , Texture , and Mechanical Property Analysis of Gas Metal Arc Welded AISI 304 Austenitic Stainless Steel," no. June 2015, 2014, doi: 10.1007/s11665-014-1374-0.

[12]F. Metal et al., "304 Stainless Steel MatWeb , Your Source for Materials Information - WWW . MATWEB . COM / MatWeb , Your Source for Materials Information - WWW . MATWEB . COM /," Source, pp. 1-2.

[13]A. Widjaya, A. N. Rabbani, K. R. A. N. Ningrum, and F. Triawan, "The Design and Analysis of a Child Seat for a Motorcycle," $J$. Mech. Eng. Mechatronics, vol. 5, no. 2, pp. 101-113, 2020.

[14]S. Zulaikah, W. H. Rahmanda, and F. Triawan, "Foldable Front Child-Seat Design for Scooter Motorcycle: Strength Analysis Under Static and Dynamic Loading," Int. J. Sustain. Transp. Technol., vol. 3, no. 2, pp. 37-44, 2020, doi: 10.31427/ijstt.2020.3.2.1.

[15]K. Saptaji, S. N. Afiqah, and R. D. Ramdan, "A Review on Measurement Methods for Machining Induced Residual Stress,' Indones. J. Comput. Eng. Des., vol. 1, no. 2, p. 106, 2019, doi: 10.35806/ijoced.v1i2.64.

[16]I. P. Nurprasetio, B. A. Budiman, and F. Triawan, "Failure investigation of plastic shredding machine's flange coupling based on mechanical analysis," Indones. J. Sci. Technol., vol. 2, no. 2, pp. 124-133, 2017, doi: 10.17509/ijost.v2i2.7988.
Table 5. Safety factor of all critical components under fatigue loading

\begin{tabular}{cc}
\hline Component & $n_{f}$ \\
\hline Scissor arm & 2.49 \\
Pin & 5.08 \\
Power screw & 3.3 \\
Connector & 3.41 \\
\hline
\end{tabular}

